\title{
Comparative Study on Seismic Performance of Cast-in-Place and Assembled Shear Walls
}

\author{
Linlin Shen*, Chao Wu, Longcheng Xing, Xiaodong Pan, Jingbo Zhou \\ College of Civil Engineering and Architecture, Hebei University, Baoding, China \\ Email: 769712060@qq.com
}

\begin{abstract}
With the rapid development of China's construction industry,the shear wall structure is more and more applied to the building. This paper uses the ABAQUS analysis software to simulate the shear wall structure with low cycle load, and analyzes and studies the seismic behavior of the shear wall with two kinds of connecting modes, cast-in-place and assembled. The hysteresis curves of two kinds of shear walls are obtained by simulation. The ultimate bearing capacity of fabricated shear wall members is slightly higher than the cast-in-place shear walls, which shows that the assembled shear wall has better seismic and energy dissipation capacity. The ductility coefficients of the two kinds of shear wall members are similar by the analysis of the displacement ductility coefficients. Compared with the two kinds of shear wall specimens, the initial stiffness of the assembled shear wall specimen is slightly larger than the cast-in-place specimen, and the stiffness of the cast-in-place shear wall specimen is relatively slow, and the two stiffness degeneration curve overlap gradually. The preliminary results show that the seismic performance of the assembled shear wall specimens satisfies the specification compared with the cast-in-place shear wall specimens.
\end{abstract}

Keywords: Cast-in-place and assembled shear wall, energy dissipation capacity, ductility, stiffnessdegeneration, seismic performance.

\section{Introduction}

We would like to draw your attention to the fact that it is not possible to modify a paper in any way, once it has been published. This applies to both the printed book and the online version of the publication. Every detail, including the order of the names of the authors, should be checked before the paper is sent to the editors. Cast-in-place Shear Wall is the most widely used form of existing engineering, and it is the most familiar to the construction industry practitioners. Generally, cast-inplace shear walls are widely used in high-rise buildings, which have the advantages of simple process, good integrity and large rigidity through the process of formwork setting, reinforcement and binding, concrete pouring and maintenance[1]. However, combined with the current situation in China, the castin-place shear Wall also has many deficiencies, as follows [2-6]: (1) A large number of workers depend on the site to do manual work, which increases the labor intensity of the construction workers and has a negative effect on the operation efficiency. Because of the long construction period and the large number of wet operations on site, the quality of the walls will be subject to many external factors, including climate. (2) A large number of people, materials and machines are needed to work together, which has raised the cost of construction. Moreover, the construction workers' ability is different, which causes the construction cost and quality to be difficult to control. (3) Site pouring has many adverse effects on the outside world, such as waste of water, air pollution, noise pollution and so on. At the same time, a large number of wood and steel are supported, building materials and electricity consumption are large, which is not conducive to the protection of the environment. (4) There must be strict safety measures to ensure the construction site. For example, the inevitable high voltage power use, high altitude high temperature operation, large mechanical equipment and so on, all of which need to provide the necessary safety equipment for the construction workers on the site, and popularize the relevant safety knowledge.

In view of the shortcomings of the cast-in-place shear wall construction, it is urgent for the construction workers to find a more reasonable and effective method to promote the rational 
development of the construction industry. Therefore, the new technology of housing industrialization and fabricated shear wall came into being [7].

Considering the high cost of the test, the long period and the higher requirements of the conditions, in this paper, the numerical simulation method is used to simulate the low cycle cyclic loading of shear walls, and the shear walls of two kinds of cast and assembly modes are evaluated synthetically by using the mature ABAQUS analysis software.

\section{$2 \quad$ Establishment of the Model}

The shear wall is designed to use the form of the shear wall with edge constraint, referring to the construction wall and reinforcement in actual construction, the reinforcement of the reinforcement of the ground beam and the loaded beam is $20 \mathrm{~mm}$, the vertical longitudinal bar has two types of $16 \mathrm{~mm}$ and $14 \mathrm{~mm}$, and the stirrup is $8 \mathrm{~mm}$, all of which are HRB400 type steel bars. The concrete size of the shear wall specimen is $2800 \mathrm{~mm} \times 1400 \mathrm{~mm} \times 200 \mathrm{~mm}$, the concrete of cast in situ shear wall (XJ) is C30, the concrete strength of the assembled precast shear wall (abbreviated as ZHD) is C30, and the middle level joint is C60 high strength concrete with steel fiber content of 1\%, and the longitudinal mixing method is used, which is compared with the cast - in - place shear wall. At present, there are four widely used constitutive models for steel bar: three broken line, whole line, bilinear model and ideal elastoplastic model. Bilinear model and ideal elastoplastic model are widely used. In this paper, the latter is analyzed by the ideal elastoplastic model, and the constitutive relation is shown in Figure 1.

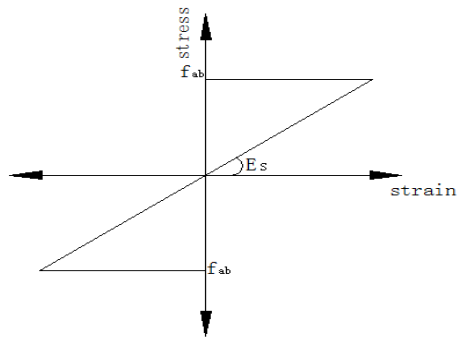

Figure 1. The constitutive relation of steel bar.

In order to ensure the comparability of the test results, the geometric size of the two shear wall specimens, the ground beam, the wall body, and the reinforcement of the loading beam are exactly the same, there is only a difference in the way of connection. In order to ensure the authenticity of the simulation test, the mechanical properties of two kinds of shear wall specimens were tested. The list is as follows:

Table 1. Prefabricated wall concrete (C30) performance.

\begin{tabular}{ccccc}
\hline $\begin{array}{c}\text { Standard test block } \\
\text { strength }(\mathbf{M P a})\end{array}$ & $\begin{array}{c}\text { Prismatic } \\
\text { strength }(\mathbf{M P a})\end{array}$ & $\begin{array}{c}\text { Splitting tensile } \\
\text { strength }(\mathbf{M P a})\end{array}$ & $\begin{array}{c}\text { Elastic Modulus } \\
(\mathbf{G P a})\end{array}$ & $\begin{array}{c}\text { Bonding strength } \\
\text { with steel }(\mathbf{M P a})\end{array}$ \\
\hline 33.8 & 23.1 & 2.71 & 31.8 & 14.78 \\
\hline
\end{tabular}

Table 2. Mechanical properties of steel bars.

\begin{tabular}{ccccc}
\hline $\begin{array}{c}\text { Reinforcement } \\
\text { diameter }\end{array}$ & $\begin{array}{c}\text { Yield Strength } \\
(\mathbf{M P a})\end{array}$ & $\begin{array}{c}\text { Ultimate yield } \\
\text { strength }(\mathbf{M P a})\end{array}$ & $\begin{array}{c}\text { Elastic Modulus } \\
(\mathbf{M P a})\end{array}$ & Poisson's ratio \\
\hline $20 \mathrm{~mm}$ & 497.4 & 596.6 & 210000 & 0.3 \\
$16 \mathrm{~mm}$ & 523.2 & 696.6 & 203000 & 0.3 \\
$14 \mathrm{~mm}$ & 504.9 & 647.4 & 201000 & 0.3 \\
$8 \mathrm{~mm}$ & 512.7 & 615.4 & 197000 & 0.3 \\
\hline
\end{tabular}


Table 3. Mechanical properties of steel fiber high strength concrete at joints.

\begin{tabular}{ccccc}
\hline $\begin{array}{c}\text { Volume } \\
\text { rate }\end{array}$ & $\begin{array}{c}\text { Compressive } \\
\text { strength }(\mathrm{MPa})\end{array}$ & $\begin{array}{c}\text { Splitting tensile } \\
\text { strength }(\mathrm{MPa})\end{array}$ & $\begin{array}{c}\text { Elastic Modulus } \\
(\mathrm{GPa})\end{array}$ & $\begin{array}{c}\text { Bonding strength with } \\
\text { steel }(\mathrm{MPa})\end{array}$ \\
\hline $1 \%$ & 66.7 & 5.86 & 4.729 & 30.14 \\
\hline
\end{tabular}

The constitutive relations of reinforced materials under ideal elastoplastic mode are as follows:

$$
\begin{array}{cc}
\sigma_{s}=E_{S} \sigma_{S} & \varepsilon_{s} \leq \varepsilon_{y} \\
\sigma_{s}=f_{y} & \varepsilon_{s} \geq f_{y}
\end{array}
$$

In the upper formula, Es is the elastic modulus and FY is yield stress.

In order to make the simulation results close to the actual situation, the model was established in the ABAQUS software according to the mechanical parameters of the materials used in the shear wall, which was measured in the mechanical test. The seismic performance of two kinds of shear walls is compared.

\section{Results Analysis}

\subsection{Stress Analysis}

Through the contrast analysis of stress cloud images of two kinds of shear walls, the MISES stress distributions of the two shear walls are similar. The maximum stress of the reinforced bar on the edge is $523.2 \mathrm{Mpa}$ to yield. In addition, because of the selection of high strength steel fiber concrete at the joint of the assembled shear wall, the maximum stress of the concrete has a small difference of $63.20 \mathrm{Mpa}$ and $52.60 \mathrm{Mpa}$, which is basically crushed and yielded at the corner of the left wall. In Figure 2 and 3 , the integrity of the cast shear wall is better. Under the action of vertical axis pressure and horizontal cyclic loading, the integrity of the assembled shear wall is slightly less than the cast shear wall.
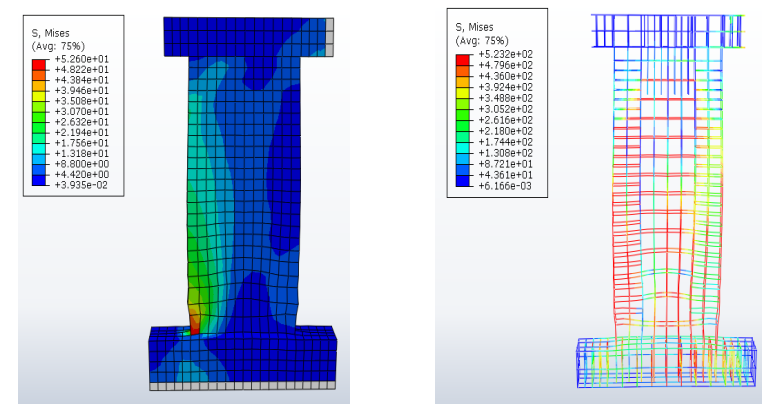

Figure 2. Concrete stress cloud chart of reinforced concrete shear wall and reinforcement stress cloud chart.
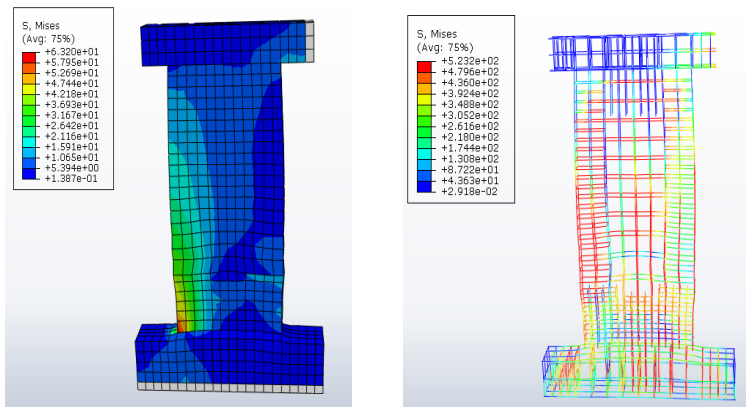

Figure 3. Concrete stress cloud chart and reinforce ment stress cloud chart of cast-in-place shear wall. 


\subsection{Analysis of Load Displacement Hysteretic Behavior of Specimen}

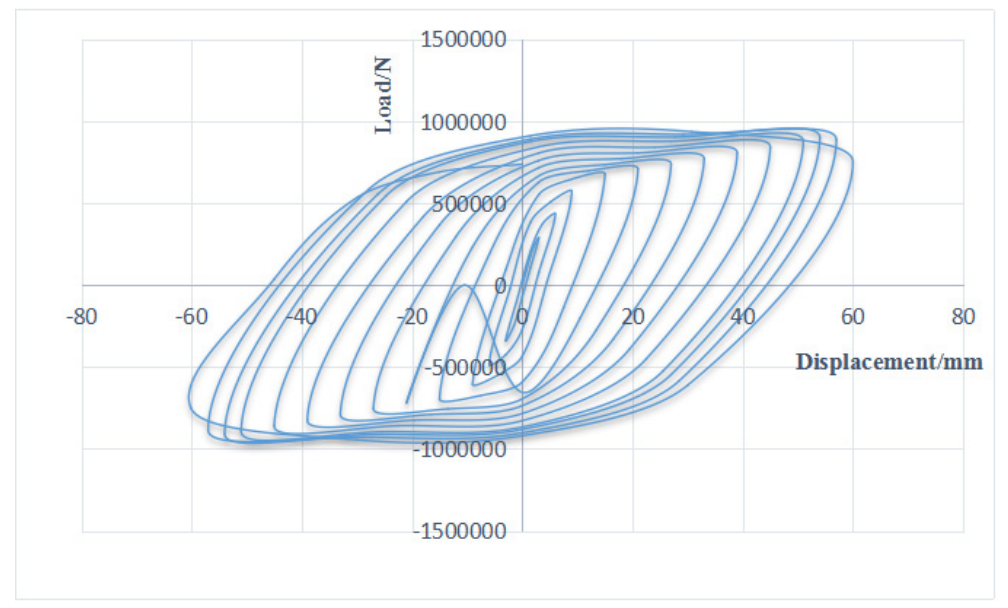

Figure 4. Hysteretic curve of cast shear wall.

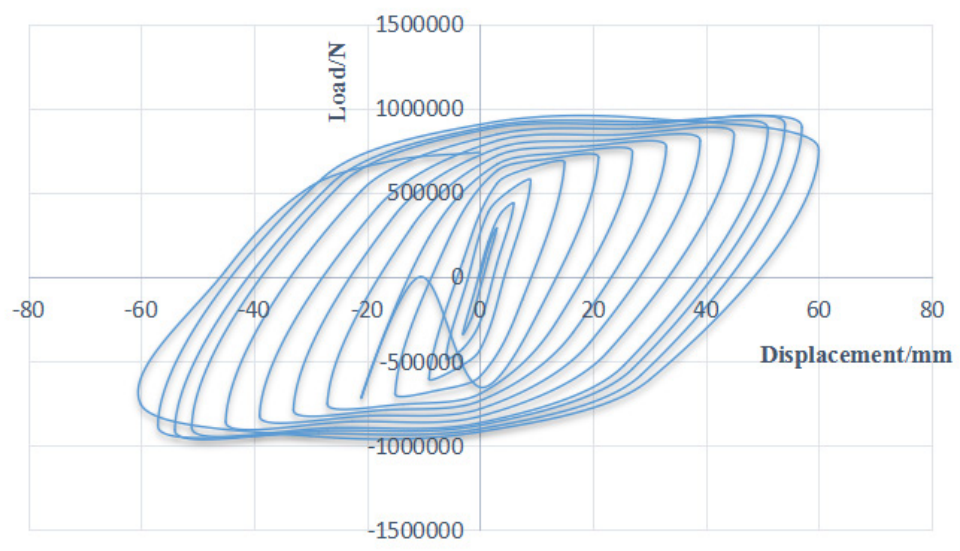

Figure 5. Hysteretic curve of assembled shear wall.

By comparing the hysteretic curves of two kinds of shear walls of Figures 4 and 5, the following characteristics can be observed: the hysteresis curves of the shear walls of the two types of connection are basically the same. The hysteresis curve of the shear walls is basically straight in the lower displacement and the area of the hysteresis loop is small, indicating that the shear wall specimens are in the elastic state. With the increase of the displacement, the hysteresis curve is bending, and the relationship between the load and the displacement is no longer linear. The stiffness of the specimen is reduced and the plastic deformation appears, and it begins to enter the elastoplastic state. The ultimate bearing capacity of ZHD shear wall specimens is slightly higher than that of XJ shear walls. The hysteresis loops of the two types of shear walls are all shuttle form, and the hysteresis loop is full. Under the load, the two shear walls have a smaller stiffness degradation. The bearing capacity of the shear wall after the peak load is basically the same, and the bearing capacity decreases more slowly. Compared with XJ shear wall specimens, ZHD shear wall specimens also have better seismic and energy dissipation capacity.

\subsection{Analysis of the Skeleton Curve of the Specimen}

The shear wall skeleton curve is used to evaluate the strength, stiffness and ductility of the shear wall members after the maximum connection of the loading horizontal force at all levels in the hysteresis 
curve of the shear wall simulation test.

Through the analysis of Figures 6 and 7, it can be found that (1) the initial stiffness of the ZHD specimen and the XJ specimen is similar; the ultimate bearing capacity of the ZHD specimen is larger than the XJ specimen; at the limit displacement, the ultimate displacement of the XJ specimen is $54 \mathrm{~mm}$, and the ultimate displacement of the ZHD specimen is $51 \mathrm{~mm}$. Through the enveloping area of skeleton curve, it is known that the energy dissipation capacity of ZHD specimen is better than that of XJ specimen. (2) through the skeleton curve, it can be observed that the two shear wall specimens of XJ and ZHD are controlled by 0.3 of the axial compression ratio, and under the condition of horizontal cyclic loading, the development trend of the skeleton curve is basically similar, and it is divided into two stages of elastic and elastoplastic. The curve of the elastic phase is steepy, and there is no abnormal sudden change. The elastoplastic stage curve extends slowly upward. After reaching the ultimate load, the structural stiffness decreases with the increase of load. The XJ and ZHD skeleton curves begin to decrease obviously, and the ZHD curve drops quickly, indicating that the stiffness degradation rate of the ZHD specimen is faster than that of the XJ specimen. The bearing capacity of XJ specimen is $83 \%$ of the ultimate bearing capacity, and the bearing capacity of ZHD specimen is $81 \%$ of the ultimate bearing capacity.
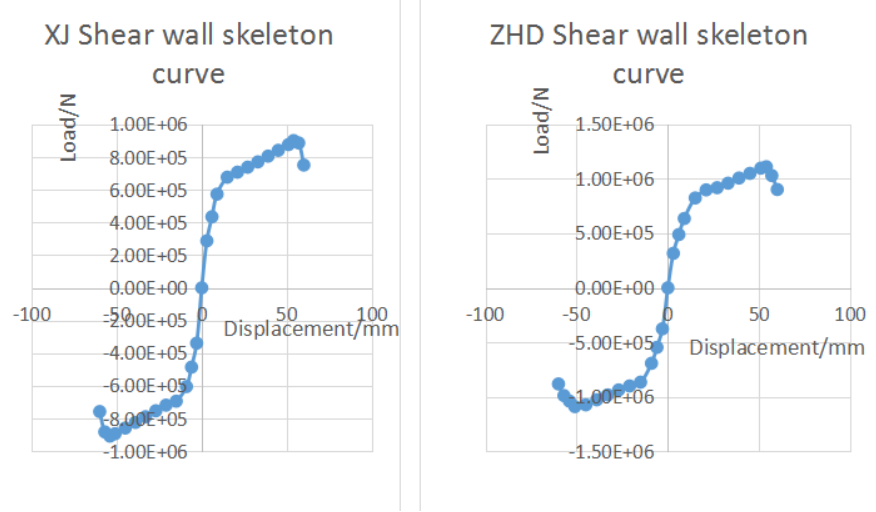

Figure 6. Contrast diagram of skeleton curve.

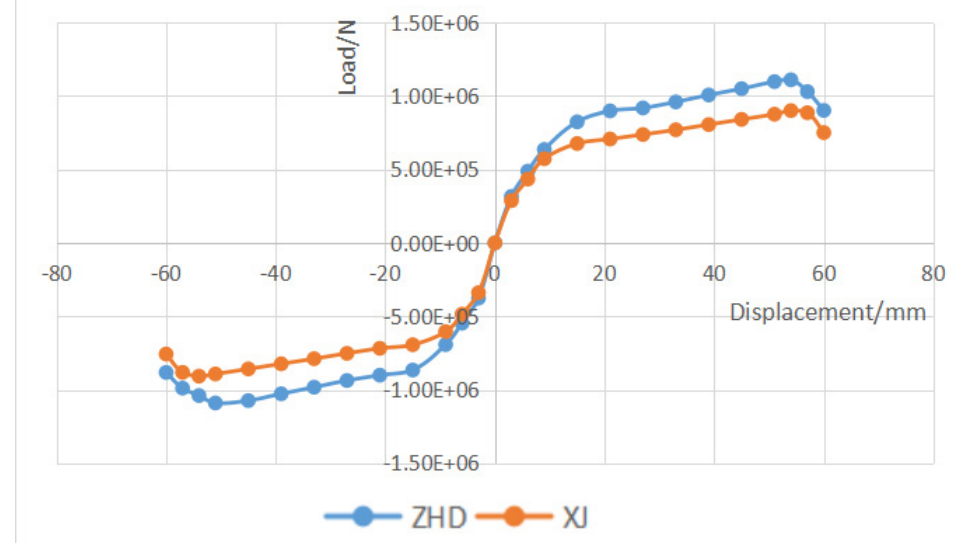

Figure 7. Cast-in-place and assembled shear wall skeleton curves.

\subsection{Comparison and Analysis of Ductility of Specimen}

The ductility of the shear wall refers to the deformation capacity of the shear wall component in its elastoplastic state, that is, after its elastic limit state, but it does not enter the obvious stage of strength and stiffness degradation. It is used to evaluate the late deformation capacity of members before failure. 
Generally, there are two evaluation methods: displacement ductility and curvature ductility. In this simulation test, the ductility of shear walls is analyzed based on the displacement ductility factor based on the displacement of shear wall components. The calculation formula is as follows:

$$
\mu_{\Delta}=\frac{\left|\Delta_{+\mu}\right|+\left|\Delta_{-\mu}\right|}{\left|\Delta_{+y}\right|+\left|\Delta_{-y}\right|}
$$

In the upper formula, $\Delta_{y}\left(\Delta_{-y}\right)$-Positive (negative) ultimate displacement of shear wall specimens $\Delta_{+\mu}\left(\Delta_{-\mu}\right)$-The positive (negative) yield displacement of the shear wall specimens.

Table 4. Displacement and ductility of the test piece.

\begin{tabular}{cccccc}
\hline & $\begin{array}{c}\text { Positive limit } \\
\text { displacement }\end{array}$ & $\begin{array}{c}\text { Negative limit } \\
\text { displacement }\end{array}$ & $\begin{array}{c}\text { Positive yield } \\
\text { displacement }\end{array}$ & $\begin{array}{c}\text { Negative yielding } \\
\text { displacement }\end{array}$ & $\begin{array}{c}\text { Ductility } \\
\text { factor }\end{array}$ \\
\hline XJ & $59.40 \mathrm{~mm}$ & $59.33 \mathrm{~mm}$ & $9 \mathrm{~mm}$ & $9 \mathrm{~mm}$ & 6.60 \\
ZHD & $58.18 \mathrm{~mm}$ & $58.05 \mathrm{~mm}$ & $9 \mathrm{~mm}$ & $9 \mathrm{~mm}$ & 6.46 \\
\hline
\end{tabular}

The ductility coefficient of the specimen is shown in Table 4 below. The judgment of yield displacement and limit displacement in the simulation test of shear wall test is mainly based on its skeleton curve. The method of judging the yield displacement is as follows: (1) the selection of yield displacement: the obvious inflection point in the skeleton curve obtained from the simulation test. (2) the selection of ultimate displacement: when the load decreases with the increase of deformation to $85 \%$ of the lowest load, this is the limit displacement point of the component. Through table 4, it can be seen that the ductility coefficient of the two shear wall specimens of XJ and ZHD is similar, the ductility coefficient of the ZHD specimen is slightly lower, but the ductility coefficient of the two shear walls is more than 6, which can be considered as a good seismic performance, which provides a good theoretical cushion for further exploration and application.

\subsection{Comparison and Analysis of Energy Dissipation Capacity of Specimen}

The energy dissipation capacity of a specimen represents its ability to absorb seismic energy, and it is an important index to measure its seismic performance. It is usually evaluated by the equivalent viscous damping ratio. The greater the equivalent viscous damping ratio, the better the energy dissipation capacity of the specimen. The concrete method is to use the load displacement hysteretic curve of the specimen to make the work of the actual damping in one cycle, and to determine the equivalent viscous damping ratio according to the principle of energy dissipation equal. Concrete schematic diagrams such as Figure 8 and calculation formula (4).

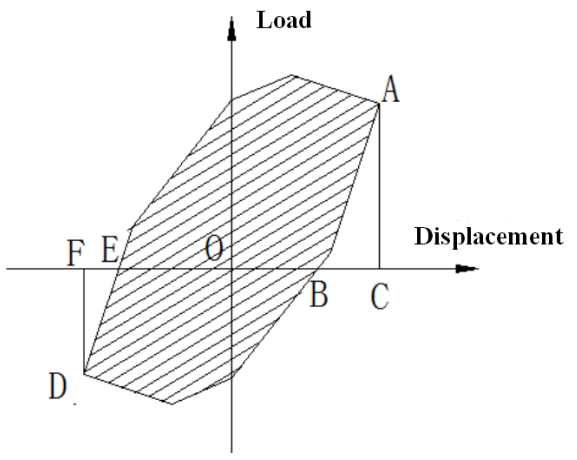

Figure 8. Schematic diagram of hysteresis curve

$$
\xi_{e q}=\frac{1}{2 \pi} \frac{S_{E A B}+S_{B D E}}{S_{\triangle O A C}+S_{\triangle O D F}}
$$


In the upper formula, SEAB, SBDE - The area of curve EAB, S $\triangle \mathrm{OAC}, \mathrm{S} \triangle \mathrm{ODF}$ - curve CDA Triangle OAC The area of the triangle ODF $\xi_{e q}$ - The equivalent viscous damping ratio.

The load displacement hysteretic curve of XJ shear wall specimens and ZHD shear wall specimens is calculated by using the upper formula, and the relationship between the displacement and the equivalent viscous damping ratio displacement of the specimens of the XJ shear wall and the ZHD shear wall is shown in Figures 9 to 10.
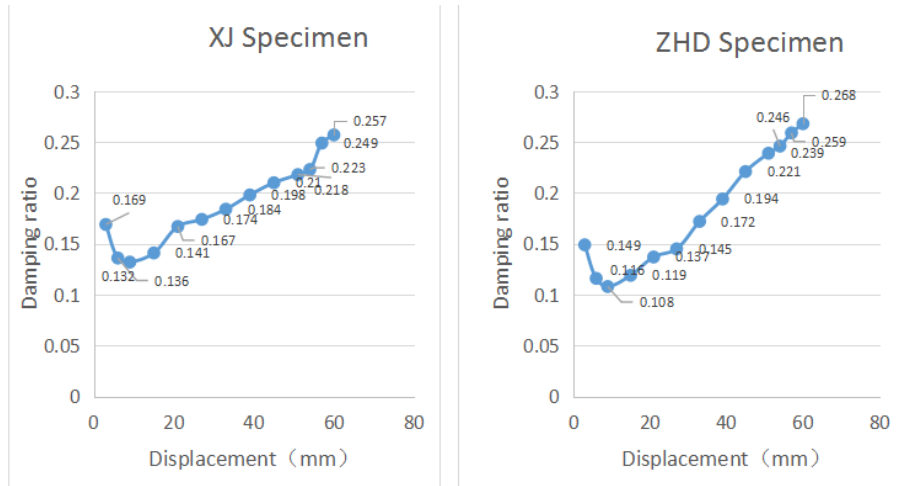

Figure 9. XJ and ZHD equivalent viscous damping ratio displacement curve.

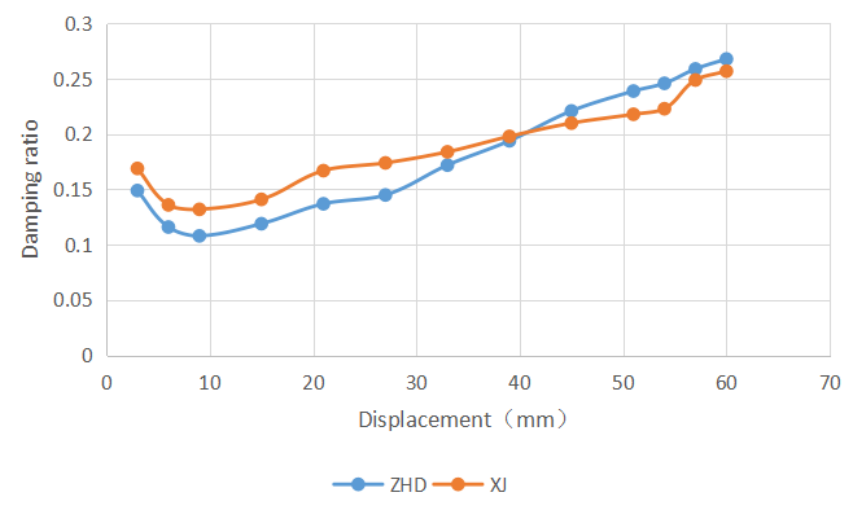

Figure 10. The comparison of ZHD and XJ equivalent viscous damping ratio.

Through the analysis of Figures 9 and 10, it can be concluded that before $15 \mathrm{~mm}$, the equivalent viscous damping ratio of the two specimens has an obvious decrease segment, and then an ascending segment. The reason is that the plasticity of the specimen is mainly manifested in the plastic deformation of the concrete. After the concrete cracking, the longitudinal reinforcement in the specimen does not yield immediately, and enters the strong elastoplastic stage, and the energy dissipation capacity increases. The development trend of two types of XJ and ZHD is similar, indicating that their energy consumption is similar. Compared with XJ specimens, ZHD specimens can meet the requirements of energy dissipation capacity.

\subsection{Comparison and Analysis of Stiffness Degradation}

During the simulation test, the stiffness of shear wall specimens will deteriorate due to irreversible damage caused by horizontal circulation. The stiffness of the specimen is evaluated by observing the equivalent stiffness of the specimen [8]. The equivalent stiffness Ki is as follows: [8]:

$$
K_{i}=\frac{\left|Q_{i}\right|+\left|-Q_{i}\right|}{\left|\Delta_{i}\right|+\left|-\Delta_{i}\right|}
$$

In the upper form, $\mathrm{Ki}$ is the equivalent stiffness of the shear wall in the cyclic displacement loading of grade i; Qi (-Qi) is the peak load in the cyclic displacement loading of the i class; and the $\Delta \mathrm{i}(-\Delta \mathrm{i})$ is 
the peak of the displacement in the cyclic displacement loading of the i grade. Figure 12 XJ and ZHD stiffness degradation curve.
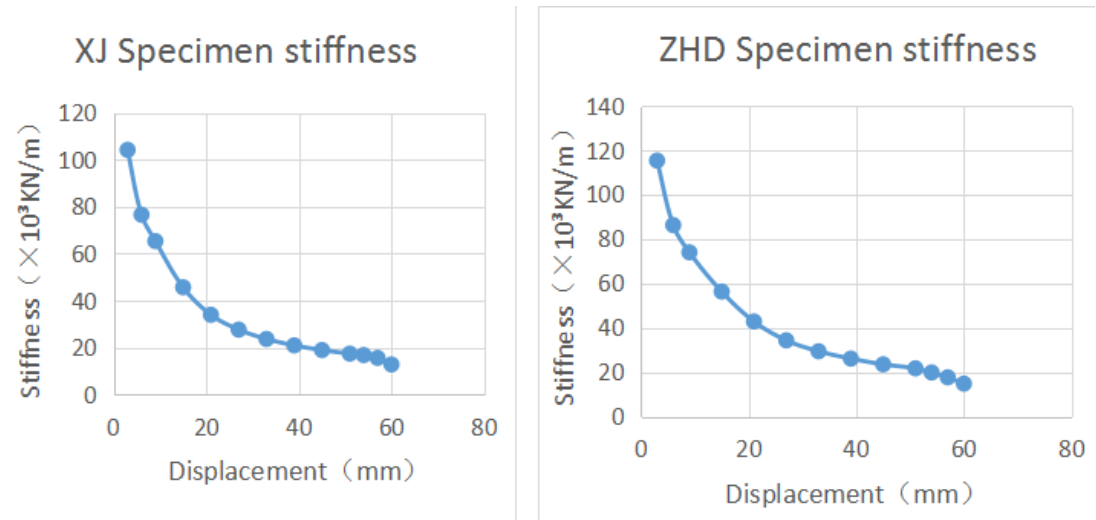

Figure 11. XJ and ZHD stiffness degradation curve.

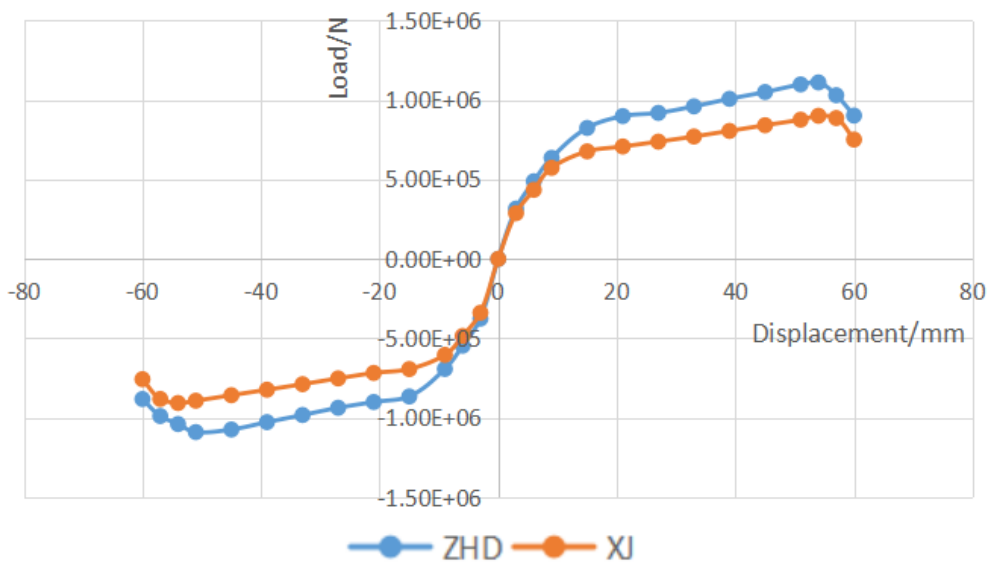

Figure 12. Comparison of stiffness degradation curves of XJ and ZHD specimens.

By comparing the stiffness degradation curves of the Figures 11 and 12 cast shear walls and the assembled shear walls, (1) by comparing the specimens of two shear walls, the initial stiffness of the ZHD specimen is slightly larger than that of the XJ specimen. (2) in the elastic stage, the stiffness decline trend of the two shear wall specimens is basically the same. After entering the elastoplastic stage, the stiffness degradation of the two shear walls gradually shows different trends. The stiffness degradation comparison diagram of the two specimens is carefully observed. It is not difficult to show that the stiffness degradation of the XJ shear wall specimens is relatively slow, and the two stiffness degradation curves coincide gradually.

\section{Conclusion}

In this paper, the hysteresis curves of two shear walls are obtained by numerical simulation. On this basis, the skeleton curves of XJ and ZHD shear wall specimens are plotted respectively. The hysteresis curves and skeleton curves of the two shear wall specimens are compared, and the similarities and differences of the ductility, stiffness degradation capacity and energy dissipation capacity are discussed in depth. It is found that the ductility coefficients of the two shear wall specimens are similar, the ultimate bearing capacity of the assembled shear wall members is slightly higher than the cast in place shear wall, which shows that the assembled shear wall has better seismic and energy dissipation capacity. The initial stiffness of the assembled shear wall specimens is slightly larger than the cast-in-place 
specimens, and the stiffness degradation of the cast-in-place shear wall specimens is relatively slow. The two stiffness degradation curves coincide gradually. It is concluded that the seismic performance of the assembled shear wall is not weaker than the cast-in-place specimen by simulation, which lays a good theoretical foundation for further expansion test and popularization in the future.

\section{References}

1. Hao C. Construction technology of high-rise cast-in-place shear wall staggered floor structure [J].Building technology, $2012(08)$.

2. Na J. Current situation and development of housing industrialization in China [J]. housing industry, 2014 (01):15-17.

3. Jungang D. The path of sustainable development of real estate economy [J]. modern economic information, 2017 (22):345.

4. Xing L,Xianguo Y, Decai W, Qing J, Lei Ch.Experimental analysis of seismic behavior of laminated plate shear walls [J]. Journal of HeFei University of Technology (NATURAL SCIENCE), 2009, 32 (08):1219-1223.

5. Min H, Qinghua Zh, Aijun W, Xu Zh, Anticorrosion full grouting sleeve used in the construction of reinforced concrete reinforced concrete structure [J]. construction, 2017, 39 (11):1640-1642.

6. Yuan Zh. Prefabricated building structural system reform design and development $[\mathrm{J}]$. northern architecture, 2018, 3 (01).

7. Xulei Z,Zhangfeng Zh. Development status of joint connection form of fabricated concrete shear wall structure [J]. concrete and cement products, 2017 (09): 51-55.

8. Dongfeng L. Seismic performance of fabricated reinforced concrete shear walls with different connections of vertical bars [D]. Chongqing University, 2016. 